Article

\title{
Shape Memory and Huge Superelasticity in Ni-Mn-Ga Glass-Coated Fibers
}

\author{
Lei Shao ${ }^{1}$, Yangyong Zhao ${ }^{1}$, Alejandro Jiménez ${ }^{2}$, Manuel Vázquez ${ }^{2}$ and Yong Zhang ${ }^{1, *}$ \\ 1 State Key Laboratory for Advanced Metals and Materials, University of Science and Technology Beijing, \\ No. 30, Xueyuan Road, Beijing 100083, China; shaoleiustb@163.com (L.S.); zhaoyangyongwd@126.com (Y.Z.) \\ 2 Institute of Materials Science of Madrid, CSIC, 28049 Madrid, Spain; ajimenezv@icmm.csic.es (A.J.); \\ mvazquez@icmm.csic.es (M.V.) \\ * Correspondence: drzhangy@ustb.edu.cn \\ Academic Editor: Alessandro Lavacchi \\ Received: 3 September 2016; Accepted: 29 December 2016; Published: 3 January 2017
}

\begin{abstract}
Ni-Mn-Ga polycrystalline alloy fibers with diameters of $33 \mu \mathrm{m}$ are reported to exhibit significantly improved ductility and huge superelastic and shape memory strains in comparison to conventional brittle bulk polycrystalline alloys. Particularly, the recoverable strain of the Ni54.9-Mn23.5-Ga21.6 fiber can be as high as $10 \%$ at $40{ }^{\circ} \mathrm{C}$. Such optimized behavior has been achieved by a suitable fabrication process via a glass-coating melt spinning method. The superelastic properties at different temperatures and the shape memory effect of Ni54.9-Mn23.5-Ga21.6 fibers were investigated.
\end{abstract}

Keywords: glass-coated melt spinning; fibers; shape memory; superelasticity; serration behavior

\section{Introduction}

The shape memory alloy (SMA) is an advanced class of smart materials that exhibit a unique phenomenon. Shape memory and superelasticity effects are believed to be driven by the crystallographically reversible martensitic transformation [1]. The shape memory behavior was first discovered in Au-Cd alloys [2] and afterwards observed in a number of systems, such as Ti-Ni, Cu-Al-Ni [3], Ni-Mn-Ga, and Ni-Co-Mn-In alloys [4-7]. Recently, novel potential systems with SMAs were reported. For example, Fe-Mn-Al-Ni SMA [1] shows a small temperature dependence of the superelastic stress. High-entropy alloy system $\mathrm{Ti}-\mathrm{Zr}-\mathrm{Hf}-\mathrm{Co}-\mathrm{Ni}-\mathrm{Cu}$ [8] shows wide temperature hysteresis of about $90 \mathrm{~K}$ at temperatures higher than $400 \mathrm{~K}$ of martensitic transformation. Fe-28Ni-17Co-11.5Al-2.5Ta-0.05B SMA [9] exhibits a superelastic strain of more than $13 \%$ with a tensile strength above $1 \mathrm{GPa}$.

SMAs have potential applications in many aspects. The thermo-mechanical properties of a number of SMAs, along with their various applications, have been presented in [10], while the most recent developments are collected in [11]. In their study, Alam et al. found that Fe-Ni-Cu-Al-Ta-B SMA fibers had a $13.5 \%$ superelastic strain and a very low austenite finish temperature $\left(-42{ }^{\circ} \mathrm{C}\right)$. Particularly, Ni-Mn-Ga alloys have been extensively explored as ferromagnetic SMAs with a giant magnetic-field-induced strain as large as $9.5 \%[6,12,13]$. Several papers revealed that a high martensitic transformation temperature (up to $350^{\circ} \mathrm{C}$ ) is observed in given Ni-Mn-Ga alloys with Ni or Mn content higher than the stoichiometric $\mathrm{Ni}_{2} \mathrm{MnGa}$ alloy, thus showing interesting potential as high-temperature SMAs [14,15]. Ma et al. [16] reported an over 6.1\% shape memory effect (SME) in Ni54-Mn25-Ga21 single crystalline alloy. Meanwhile, a well-pronounced superelastic effect as large as $6 \%$ caused by stress-induced martensitic transformation in some high-temperature single crystalline $\mathrm{Ni}-\mathrm{Mn}-\mathrm{Ga}$ alloys were reported by Chernenko et al. [17]. 
However, it is known that the polycrystalline Ni-Mn-Ga alloys are extremely brittle. Up to now, few studies have been reported in connection with their mechanical behavior, superelasticity, and SME. Li et al. [18] reported that the mechanical and shape memory characteristics of the polycrystalline Ni54-Mn25-Ga21 SMA rods, fabricated by copper mold suction method with high cooling rate, could be improved by grain refinement. However, as the grain size is still as large as 10 to $50 \mu \mathrm{m}$, the recovery ratio of the rods is less than $70 \%$, and the maximum shape memory strain is only $4.2 \%$. In-rotating-water-quenching technique was previously used to fabricate a $\mathrm{Ni}-\mathrm{Mn}-\mathrm{Ga}$ fiber about $170 \mu \mathrm{m}$ in diameter with reduced magnetization and broad martensitic transformation, but the mechanical properties were not greatly improved [19]. Our previous work reported a Ni53.96-Mn24.12-Ga21.92 fiber exhibiting large superelasticity at room temperature [20]. Here, we report the Ni-Mn-Ga fibers, made by glass-coated melt spinning method, which has a higher cooling rate, showing perfect shape memory effect. In addition, the superelastic properties at different temperatures were investigated.

\section{Materials and Methods}

Glass-coated fibers with different diameters were prepared by glass-coated melt spinning method as shown in Figure 1 [21-23]. An ingot with a nominal composition of Ni53-Mn26-Ga21 was prepared by arc melting the mixture of $\mathrm{Ni}, \mathrm{Mn}$, and $\mathrm{Ga}$ with a purity higher than $99.9 \mathrm{wt} \%$ under a Ti-gettering argon atmosphere. To achieve a homogeneous distribution of elements in the alloys, each alloy was remelted five times. Afterward, the glass-coated melt spinning method, as described elsewhere, was employed to fabricate samples in the shape of fibers [24]. Briefly, the ingot was crushed into pieces, and $3 \mathrm{~g}$ of alloy was placed in a borosilicate glass tube with an inner diameter of $8 \mathrm{~mm}$. The heating current are increased to 600 amperes gradually by a high-frequency inductor heater, and the tube and alloy are heated to around $1200{ }^{\circ} \mathrm{C}$ under an argon atmosphere. While the alloy melts, the softened glass is drawn down into a fine capillary containing the alloy melt by a glass bar with a super thin tip. The molten alloy inside solidifies rapidly into a metallic fiber by pulling the capillary through cooling water. The diameter of fibers and glass thickness are determined by the rotating speed of the winding wheel. The microstructure of a fiber depends mainly on the cooling rate, which can be controlled by a cooling mechanism when the metal-filled capillary enters water or air on its way to the receiving coil. Finally, the glass coating on the pieces of the fibers for SME and the superelasticity experiments was removed mechanically and carefully.

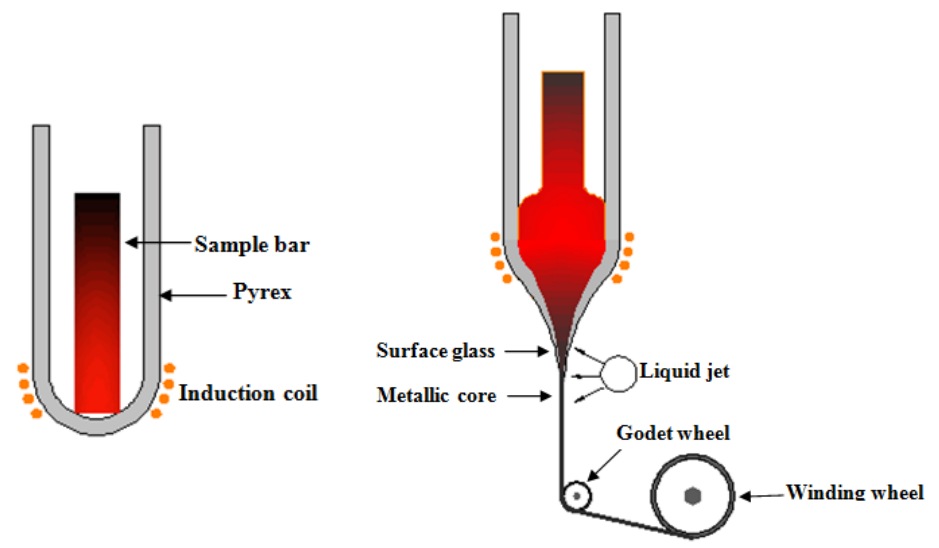

Figure 1. Schematic illustration of the Taylor technology for preparation of fibers.

The surface morphology and the composition were examined by scanning electron microscopy (SEM) and energy dispersive spectrometry (EDS), respectively. In order to analyze the superelastic properties of the fiber, isothermal uniaxial tensile tests were done in a dynamic mechanical analyzer (DMA). Each end of the fiber is mounted in a specially designed paper frame with a rhombic hole at 
the center by epoxy adhesive. When the testing sample was fixed at the two gripping ends, the paper frame was cut off by the middle. No special surface preparation was conducted on the fibers. The fiber with an initial gauge length of about $5 \mathrm{~mm}$ was heated up to $60^{\circ} \mathrm{C}$ and kept for $5 \mathrm{~min}$, then cooled to $30{ }^{\circ} \mathrm{C}$, and then subjected to a tensile load-unload cycle with a strain rate of $3.33 \times 10^{-4} \mathrm{~s}^{-1}$. After the tensile test at $30^{\circ} \mathrm{C}$, the fiber was heated up to $40{ }^{\circ} \mathrm{C}$ and kept for $5 \mathrm{~min}$, then the loaded-unloaded tensile test was performed at different strains. Similarly, the fiber was heated up to 50 and $60{ }^{\circ} \mathrm{C}$ for the same loaded-unloaded tensile test.

The prepared fibers as shown in Figure 2 are shinning and ductile and can be deformed into the shape of the letters $\mathrm{U}, \mathrm{S}, \mathrm{T}$, and $\mathrm{B}$.

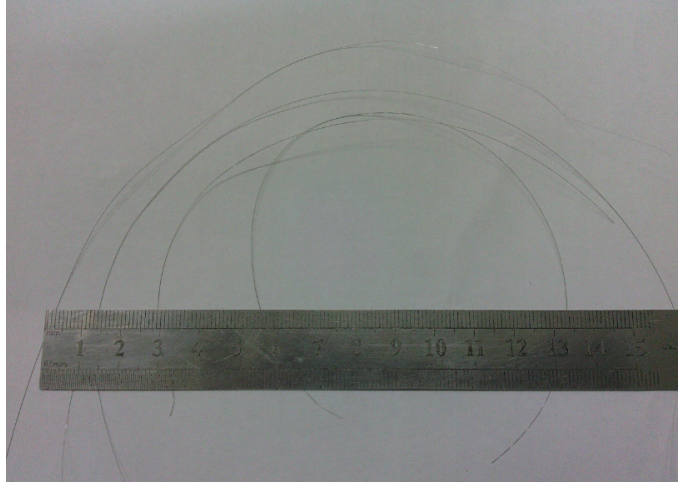

(a)

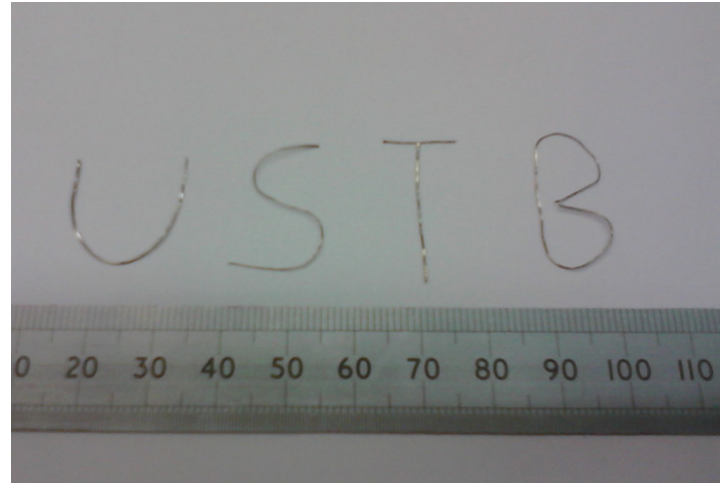

(b)

Figure 2. Pictures of the glass-coated fibers with composition of Ni53-Mn26-Ga21 (a) and deformed in to the letters U, S, T, and B with the fibers Ni55-Mn24-Ga21 (b).

The shape memory experiments of the fiber were carried out by a dynamic mechanical analyzer (DMA), where the fiber was loaded to $0.05 \mathrm{~N}(\sim 58 \mathrm{MPa})$ at room temperature before it was heated to $60{ }^{\circ} \mathrm{C}$. While maintaining this constant load, the fiber was subjected to a thermal cycle across the transformation temperature range from 60 to $-70{ }^{\circ} \mathrm{C}$. The stress-assisted SME of the Ni54.9-Mn23.5-Ga21.6 fiber was observed by DMA.

\section{Experimental Results and Their Analysis}

Figure 3 shows the morphology of surfaces and polished cuts of the fibers for Ni54.9-Mn23.5Ga21.6 (Figure 3a,b); Ni55.7-Mn23.3-Ga21.0 (Figure 3c,d); Ni56.6-Mn22.4-Ga21.0 (Figure 3e,f). It can be seen that the fibers are very uniform and with a smooth surface, and the grain sizes can be in the sub-micro and micrometer range.

Figure 4a shows the outer appearance of an as-cast fiber with a diameter of $33 \mu \mathrm{m}$. The surface is precisely circular, and the diameter of the fiber exhibits a higher uniformity than the fibers prepared by the melt extracted method [25], which demonstrates the suitability of the glass-coated melt spinning method for producing Ni-Mn-Ga fibers. Some cellular grains with a size less than $1 \mu \mathrm{m}$ could be detected on the surface as shown in Figure $1 \mathrm{~b}$, that denotes that the grain size of the fiber is greatly refined by the super cooling rate. The composition of the fiber examined by EDS is Ni54.9-Mn23.5-Ga21.6.

The stress-strain curves for the same fiber tested at different temperatures are shown as Figure 5. A uniaxial tensile strain is applied before unloading at the same rate. Since the fibers show austenite phase at these temperatures, the strain accumulated during loading beyond the elastic regime is caused by the stress-induced martensitic transformation, and this strain almost completely recovers after unloading with the reverse transformation. The fiber shows a perfect superelasticity behavior in a comparatively broader temperature region (from 30 to $60^{\circ} \mathrm{C}$ ). Differently to the stress-strain curves in Ni-Mn-Ga single crystals, many serration flows occurred during the transformation $[18-20,25,26]$. 


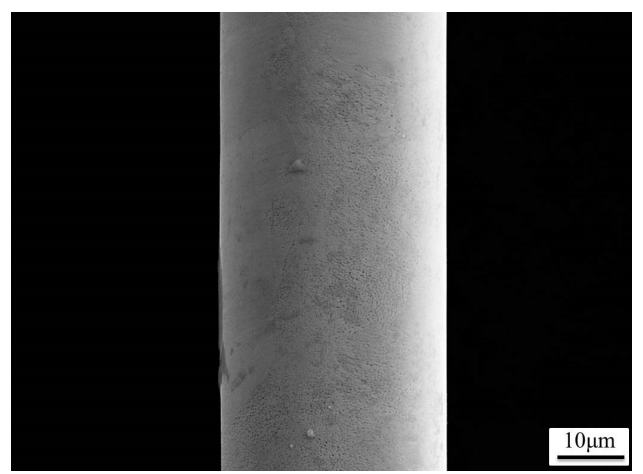

(a)

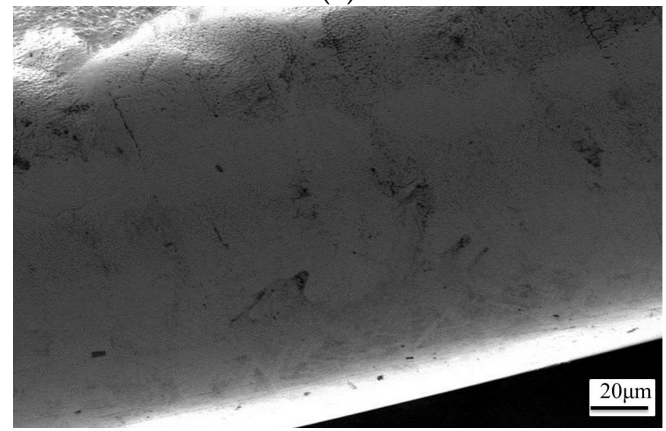

(c)

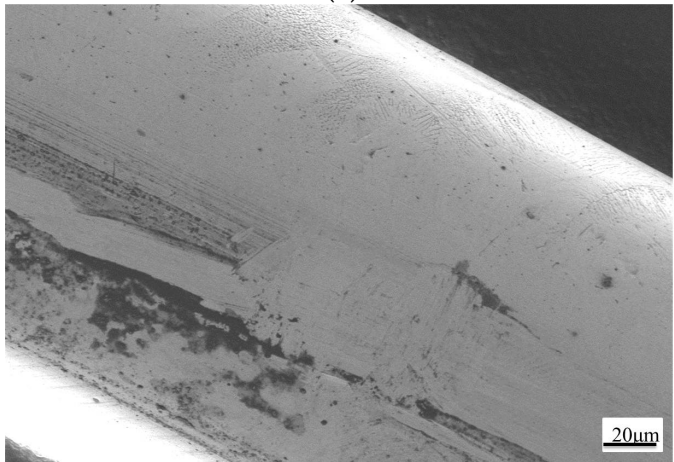

(e)

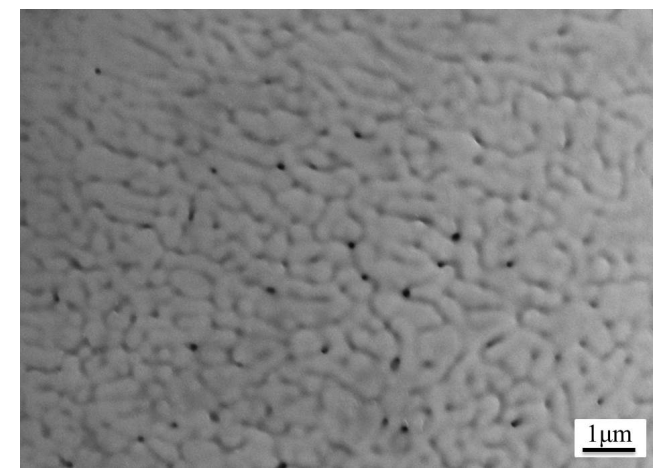

(b)

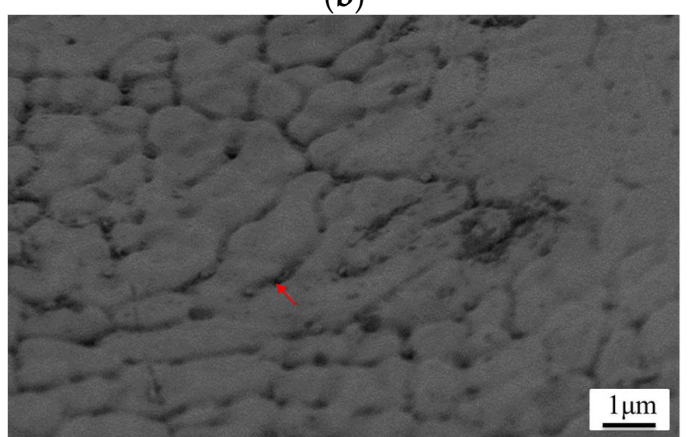

(d)

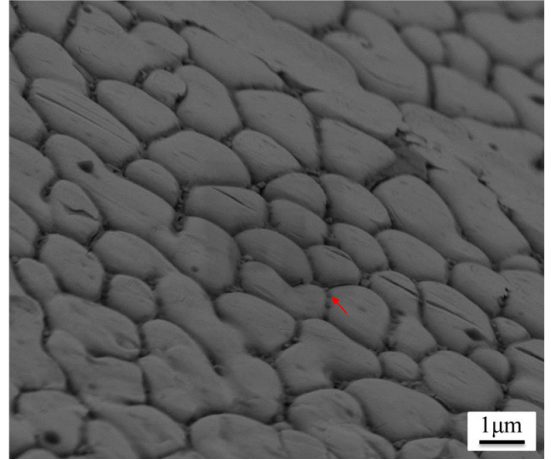

(f)

Figure 3. Morphology of surfaces and polished cuts of the fibers. (a,b) Ni54.9-Mn23.5-Ga21.6; (c,d) Ni55.7-Mn23.3-Ga21.0; (e,f) Ni56.6-Mn22.4-Ga21.0.

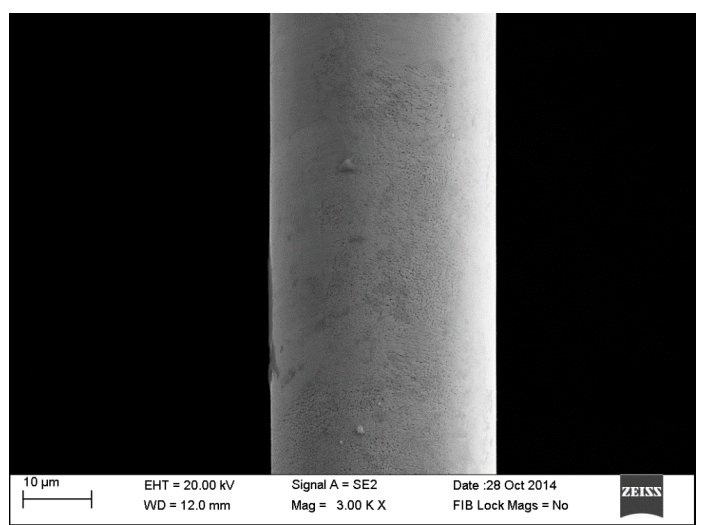

(a)

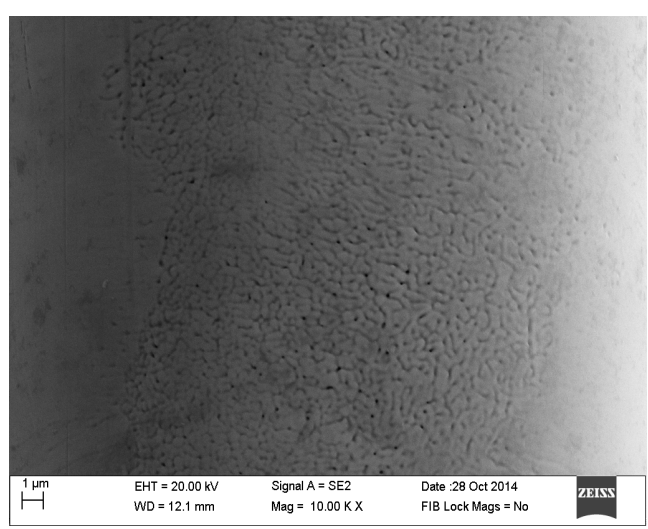

(b)

Figure 4. Morphology of the fibers. (a) SEM micrograph of the Ni54.9-Mn23.5-Ga21.6 fiber with a diameter of $33 \mu \mathrm{m}$; (b) magnified image of the surface. 


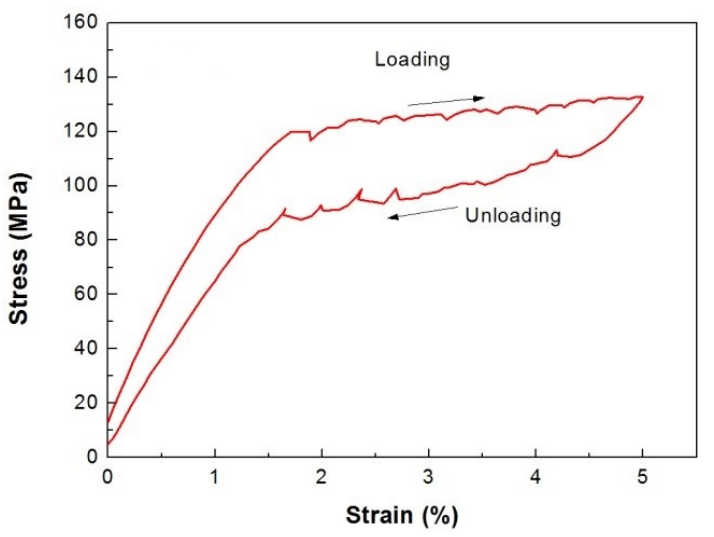

(a)

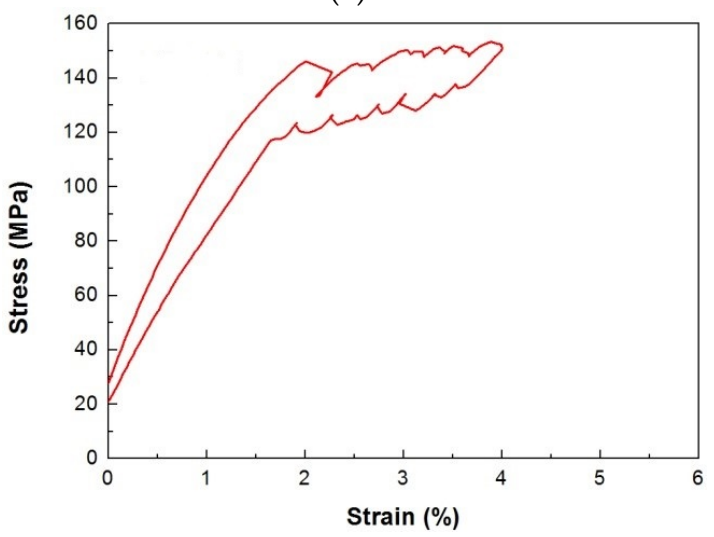

(c)

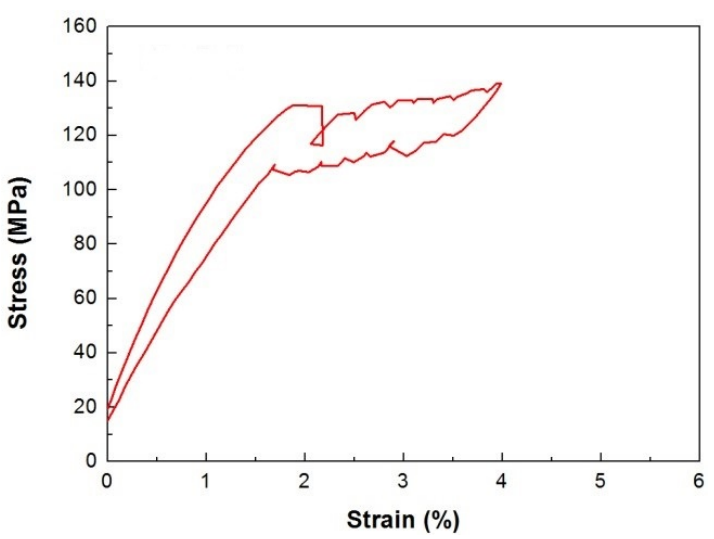

(b)

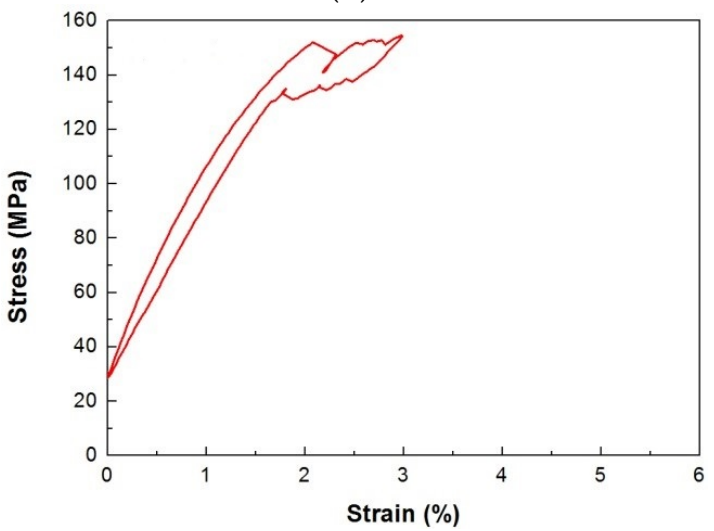

(d)

Figure 5. Tensile stress-strain curves of Ni54.9-Mn23.5-Ga21.6 fiber at different temperatures. (a) $30^{\circ} \mathrm{C}$; (b) $40{ }^{\circ} \mathrm{C}$; (c) $50{ }^{\circ} \mathrm{C}$; (d) $60{ }^{\circ} \mathrm{C}$.

The critical stress for the stress-induced martensitic (SIM) transformation, $\sigma$, which corresponds to the applied stress when the martensitic transformation starts, is plotted against temperature, $T$, in Figure 6. It increases with increasing temperature in agreement with the Clausius-Clapeyron relationship:

$$
\frac{\mathrm{d} \sigma}{\mathrm{d} T}=-\frac{\Delta S}{\varepsilon \cdot V_{m}}
$$

where $\Delta S$ is the molar entropy difference between the parent and martensite phases, $\varepsilon$ is the strain caused by the phase transformation, and $V_{\mathrm{m}}$ is the molar volume. The resulting stress-temperature slope, $\mathrm{d} \sigma / \mathrm{dT}$, is $1.1 \mathrm{MPa} /{ }^{\circ} \mathrm{C}$.

Table 1 summarizes the comparative stress-temperature slope, $\mathrm{d} \sigma / \mathrm{d} T$, for the fiber in the present work with that of Ni-Mn-Ga single crystalline and Ni49.9-Mn28.6-Ga21.5 fibers made by melt extraction. As observed, the fiber investigated in this work presents the weakest temperature dependence. This is interpreted to be the reason why the fiber show superelasticity in a wide temperature range from 30 to $60^{\circ} \mathrm{C}$, while the Ni49.9-Mn28.6-Ga21.5 fiber only shows significant superelasticity in a shorter range, i.e., from 28 to $35^{\circ} \mathrm{C}$ [25].

On the other hand, the present Ni54.9-Mn23.5-Ga21.6 fiber exhibits repeatable superelastic strains of a magnitude five times higher than polycrystalline the Ni49.9-Mn28.6-Ga21.5 fiber [25]. The superelastic recoverable strain for this fiber is as large as $\sim 10 \%$ in Figure $7 \mathrm{a}$, which is also larger than the reported recoverable strain of 6\% in the Ni53.1-Mn26.6-Ga20.3 and Ni51.2-Mn31.1-Ga17.7 single crystallines [17] and 5\% in the Ni55-Mn20-Ga25 single crystalline [27]. Here, it should be noted that the recoverable strain of the fiber is obtained in tensile mode, while it is in compressive mode for all reported single crystalline systems. 
As shown in Figure 7b, the Ni54.9-Mn23.5-Ga21.6 fiber elongates at low temperatures when it undergoes the martensitic transformation, while it contracts at high temperature when it transforms to austenite. The fiber exhibits perfect stress-assisted SME by which the strain caused by the martensitic transformation during cooling is nearly completely recovered by the reverse transformation during heating.

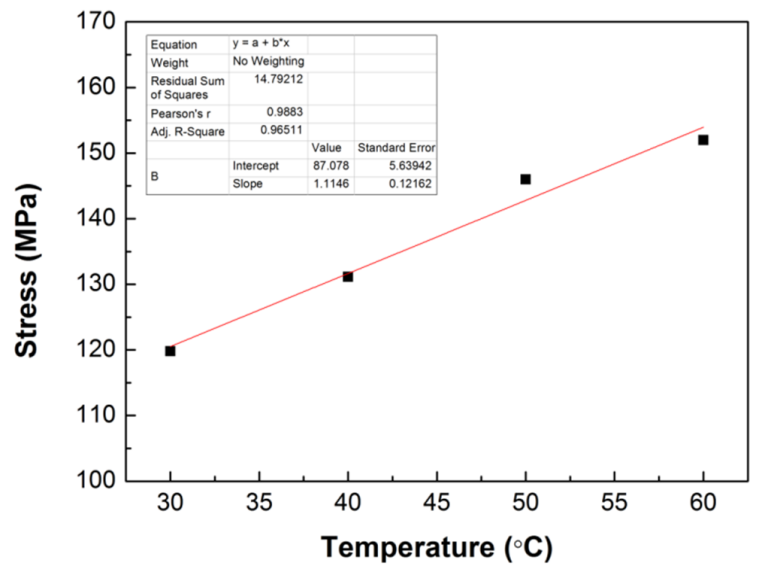

Figure 6. The critical SIM formation stress vs. temperature in the Ni54.9-Mn23.5-Ga21.6 fiber.

Table 1. The stress-temperature slope, $\mathrm{d} \sigma / \mathrm{d} T$, and recoverable strain of Ni-Mn-Ga single crystalline and fibers made by melt extraction.

\begin{tabular}{ccc}
\hline Compositions & $\mathrm{d} \sigma / \mathbf{d} T\left(\mathbf{M P a} /{ }^{\circ} \mathbf{C}\right)$ & Recoverable Strain (\%) \\
\hline Ni53.1-Mn26.6-Ga20.3 & $1.9[001], 3.4[110]$ & $6 \%$ \\
Ni51.2-Mn31.1-Ga17.7 & $2.8[001], 5.2[110]$ & $6 \%$ \\
Ni55-Mn20-Ga25 & $2.9[100]$ & $5 \%$ \\
Ni49.9-Mn28.6-Ga21.5 fiber & 8.7 & $2 \%$ \\
Ni54.9-Mn23.5-Ga21.6 [this work] & 1.1 & $10 \%$ \\
\hline
\end{tabular}

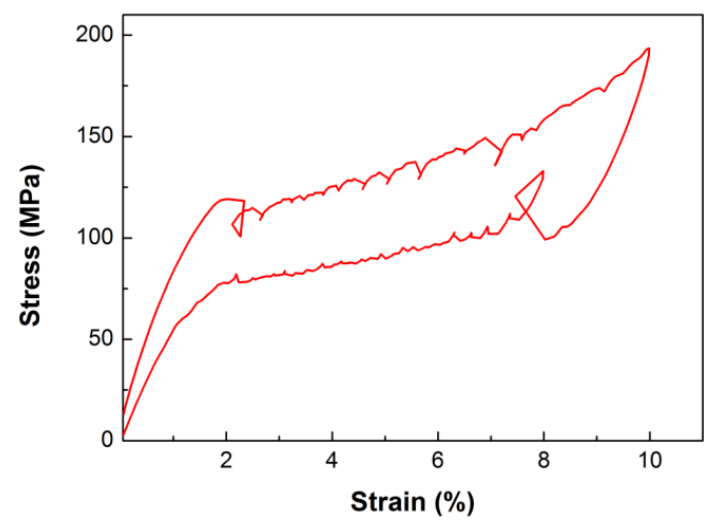

(a)

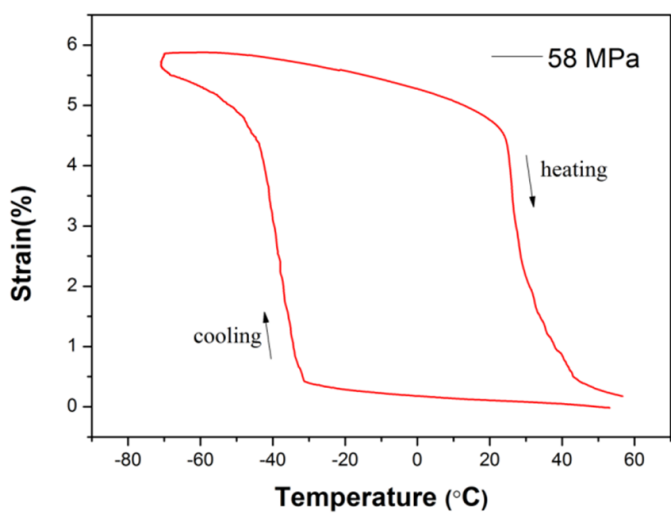

(b)

Figure 7. (a) Stress-strain curves for Ni54.9-Mn23.5-Ga21.6 fiber unloaded from $10 \%$ strain at $40{ }^{\circ} \mathrm{C}$ (b) Stress-assisted shape memory effect of the Ni54.9-Mn23.5-Ga21.6 fiber under constant tensile load of $0.05 \mathrm{~N}(\sim 58 \mathrm{MPa})$.

\section{Discussion}

Figure 6 and Table 1 show that the fibers presented in this work have the smallest stress-temperature slope (1.1) and the largest recoverable strain (10\%). The properties may be due to the high cooling rate of the glass-coated melt-spinning technique. For forming the micro-sized fiber, 
the cooling rate can be about $10^{6} \mathrm{~K} / \mathrm{s}$, which will greatly suppress the grain segregations and refine the grains. Moreover, the fibers by this technique are usually with more smooth surface and roundness shape. This is much better than the technique by the melt extraction technique as listed in Table 1 [17]. The properties of the bulk samples and the foam samples are not so good as that by the glass-coated melt-spinning technique, and the reason is believed to be the brittleness of the samples, which has hidden the SIM effect.

From Equation (1), we can see that the critical stress of the SIM is a temperature-dependent parameter. The parameter, $\mathrm{d} \sigma / \mathrm{d} T$, is a function of $S$, (the molar entropy difference between the parent and martensite phases), $\varepsilon$, (the strain caused by the phase transformation), and $V_{\mathrm{m}}$, (the molar volume). The fiber investigated in this work presents the weakest temperature dependence. The lowest value of the $\mathrm{d} \sigma / \mathrm{d} T=1.1 \mathrm{MPa} /{ }^{\circ} \mathrm{C}$, may be due to the small value of the entropy difference between the austenite and martensite. The high cooling rate by the technique here, which may keep most of the configurations of the father phase, makes the difference between the father phase and son phase smaller.

The serration behavior is a very important phenomena in the materials science field $[26,28]$. The serration behavior observed in the present results, as shown in Figures 5 and $7 \mathrm{a}$, is interpreted to correlate to the localized martensite phase transformation as shown in Figure 8. Similar results are also reported in $[3,20,26]$.

From Figure 8, when the tensile stress reaches a value, martensite will be locally formed, as shown by the red-colored region in Figure 8. The locally formed martensite phase may induce serration behavior on the stress-strain curve because this SIM may not be a continuous process and may cause a jump in the stress at the macroscale. SIM is very similar to transformation-induced plasticity (TRIP) steels, and the serration behavior has also been reported in other references $[20,26]$.

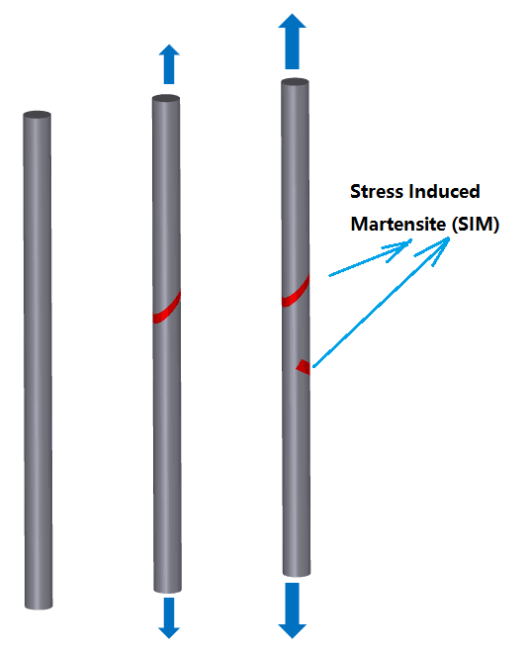

Figure 8. A schematic picture showing the SIM, which results the serration behavior in Figures 4 and 6a.

\section{Conclusions}

To summarize, Ni54.9-Mn23.5-Ga21.6 fibers with a $33 \mu \mathrm{m}$ diameter were obtained by a glass-coated melt spinning method. The superelasticity and shape memory characteristics of the polycrystalline $\mathrm{Ni}-\mathrm{Mn}-\mathrm{Ga}$ fiber can be greatly improved by this technique.

The recoverable strain of the Ni54.9-Mn23.5-Ga21.6 fiber is as high as $10 \%$ at $40{ }^{\circ} \mathrm{C}$, and the fiber shows superelasticity in a wide temperature range from 30 to $60^{\circ} \mathrm{C}$ compared with Ni-Mn-Ga fibers [22]. The mechanism may be due to a different martensite structure.

This achievement was enabled using a glass-coating melt spinning method under suitable fabrication parameters. 
Acknowledgments: Y. Zhang would like to acknowledge the financial support of the National Natural Science Foundation of China (NSFC, Granted No. 51471025). Y. Zhao would like to acknowledge the financial support from the doctoral short-term visiting scholarship program by USTB. Research at ICMM/CSIC was supported by the Regional Government of Madrid under Project S2013/MIT-1942850 NANOFRONTMAG-CM. Y. Zhang would like thank the technique help by D.Y. Li.

Author Contributions: L.S. and Y.Z. conceived and designed the experiments; L.S. and Y.Z. performed the experiments; L.S. and Y.Z. analyzed the data; A.J. and M.V. contributed reagents/materials/analysis tools; L.S. and Y.Z. wrote the paper.

Conflicts of Interest: The authors declare no conflict of interest.

\section{References}

1. Omori, T.; Ando, K.; Okano, M.; Xu, X.; Tanaka, Y.; Ohnuma, I.; Kainuma, R.; Ishida, K. Superelastic effect in polycrystalline ferrous alloys. Science 2011, 333, 68-71. [CrossRef] [PubMed]

2. Ölander, A. An electrochemical investigation of solid cadmium-gold alloys. J. Am. Chem. Soc. 1932, 54, 3819-3833. [CrossRef]

3. Li, D.Y.; Zhang, S.L.; Liao, W.B.; Geng, G.H.; Zhang, Y. Superelasticity of Cu-Ni-Al shape-memory fibers prepared by melt extraction technique. Int. J. Menerals Metall. Mater. 2016, 23, 928-933. [CrossRef]

4. Otsuka, K.; Ren, X. Physical metallurgy of Ti-Ni-based shape memory alloys. Prog. Mater. Sci. 2005, 50, 511-678. [CrossRef]

5. Chen, Y.; Zhang, X.; Dunand, D.C.; Schuh, C.A. Shape memory and superelasticity in polycrystalline Cu-Al-Ni microfibers. Appl. Phys. Lett. 2009, 95, 171906. [CrossRef]

6. Sozinov, A.; Likhachev, A.A.; Lanska, N.; et al. Giant magnetic-field-induced strain in NiMnGa seven-layered martensitic phase. Appl. Phys. Lett. 2002, 80, 1746-1748. [CrossRef]

7. Kainuma, R.; Imano, Y.; Ito, W.; Sutou, Y.; Morito, H.; Okamoto, S.; Kitakami, O.; Oikawa, K.; Fujita, A.; Kanomata, T.; et al. Magnetic-field-induced shape recovery by reverse phase transformation. Nature 2006, 439, 957-960. [CrossRef] [PubMed]

8. Firstov, G.S.; Kosorukova, T.A.; Yu, N.K.; Odnosum, V.V. High entropy shape memory alloys. Mater. Today Proc. 2015, 2, S499-S503. [CrossRef]

9. Tanaka, Y.; Himuro, Y.; Kainuma, R.; Sutou, Y.; Omori, T.; Ishida, K. Ferrous polycrystalline shape-memory alloy showing huge superelasticity. Science 2010, 327, 1488-1490. [CrossRef] [PubMed]

10. Alam, M.S.; Youssef, M.A.; Nehdi, M. Utilizing shape memory alloys to enhance the performance and safety of civil infrastructure. A review. Can. J. Civ. Eng. 2007, 34, 1075-1086. [CrossRef]

11. Dezfuli, F.H.; Alam, M.S. Shape memory alloy wire-based smart natural rubber bearing. Smart Mater. Struct. 2013, 22, 045013. [CrossRef]

12. Ullakko, K.; Huang, J.K.; Kantner, C.; O’Handley, R.C. Large magnetic-field-induced strains in Ni2MnGa single crystals. Appl. Phys. Lett. 1996, 69, 1966-1968. [CrossRef]

13. Chmielus, M.; Zhang, X.X.; Witherspoon, C.; Dunand, D.C.; Müllner, P. Giant magnetic-field-induced strains in polycrystalline Ni-Mn-Ga foams. Nat. Mater. 2009, 8, 863-866. [CrossRef] [PubMed]

14. Chernenko, V.A.; Cesari, E.; Kokorin, V.V.; Vitenko, I.N. The development of new ferromagnetic shape memory alloys in Ni-Mn-Ga system. Scr. Metall. Mater. 1995, 33, 1239-1244. [CrossRef]

15. Jin, X.; Marioni, M.; Bono, D.; Allen, S.M.; O'Handley, R.C. Empirical mapping of Ni-Mn-Ga properties with composition and valence electron concentration. J. Appl. Phys. 2002, 91, 8222. [CrossRef]

16. Xu, H.B.; Ma, Y.Q.; Jiang, C.B. A high-temperature shape-memory alloy Ni54MnGa21. Appl. Phys. Lett. 2003, 82, 3206-3208. [CrossRef]

17. Chernenko, V.A.; L'Vov, V.; Pons, J.; Cesari, E. Superelasticity in high-temperature Ni-Mn-Ga alloys. J. Appl. Phys. 2003, 93, 2394. [CrossRef]

18. Li, Y.; Xin, Y.; Jiang, C.; Xu, H. Shape memory effect of grain refined Ni54Mn25Ga21 alloy with high transformation temperature. Scr. Mater. 2004, 51, 849-852. [CrossRef]

19. Gómez-Polo, C.; Pérez-Landazábal, J.I.; Recarte, V.; Sánchez-Alarcos, V.; Badini-Confalonieri, G.; Vázquez, M. $\mathrm{Ni}-\mathrm{Mn}-\mathrm{Ga}$ ferromagnetic shape memory wires. Appl. Phys. Lett. 2010, 107, 123908. [CrossRef]

20. Zhang, Y.; Li, M.; Wang, Y.D.; Lin, J.P.; Dahmen, K.A. Superelasticity and serration behavior in small-sized NiMnGa alloys. Adv. Eng. Mater. 2014, 16, 955-960. [CrossRef] 
21. Zhao, Y.; Hao, H.; Zhang, Y. Preparation and giant magneto-impedance behavior of Co-based amorphous wires. Intermetallics 2013, 42, 62-67. [CrossRef]

22. Zhang, Y.; Zhao, Y.Y.; Liao, W.B. An Instrument for Continuous Preparing Amorphous Wires. China Patent CN102127720A, 2011.

23. Zhang, Y.; Zhao, Y.Y.; Shao, L. Preparation of a NiMnGa Shape Memory Alloy Wire. China Patent CN105316527A, 2016.

24. Zhao, Y.Y.; Li, H.; Hao, H.Y.; Li, M.; Zhang, Y.; Liaw, P.K. Microwires fabricated by glass-coated melt spinning. Rev. Sci. Instrum. 2013, 84, 75102. [CrossRef] [PubMed]

25. Qian, M.F.; Zhang, X.X.; Witherspoon, C.; Sun, J.F.; Müllner, P. Superelasticity and shape memory effects in polycrystalline Ni-Mn-Ga microfibers. J. Alloys Compd. 2013, 577, S296-S299. [CrossRef]

26. Zhang, Y.; Qiao, J.; Liaw, P.K. A brief review of high entropy alloys and serration behavior and flow units. J. Iron Steel Res. Int. 2016, 1, 2-6. [CrossRef]

27. Pasquale, M.; Sasso, C.P.; Lewis, L.H.; Giudici, L.; Lograsso, T.; Schlagel, D. Magnetostructural transition and magnetocaloric effect in Ni55Mn20Ga25 single crystals. Phys. Rev. B 2005, 72, 94435. [CrossRef]

28. Li, J.; Yang, X.; Zhu, R.; Zhang, Y. Corrosion and serration behaviors of TiZr0.5NbCr0.5V $\mathrm{V}_{\mathrm{x}} \mathrm{Mo}_{\mathrm{y}}$ high entropy alloys in aqueous environments. Metals 2014, 4, 597-608. [CrossRef]

(C) 2017 by the authors; licensee MDPI, Basel, Switzerland. This article is an open access article distributed under the terms and conditions of the Creative Commons Attribution (CC-BY) license (http://creativecommons.org/licenses/by/4.0/). 